\title{
relazioni
}

\section{SESSIONE 8}

\section{Aggiornamento sulle infezioni del sistema nervoso centrale}

Venerdi I 4 ottobre 2005, ore 09.00 - 13.00, Sala E

\section{Blasi E.}

Università di Modena e Reggio Emilia,

Dip. Sc. Igien., Microbiol., Biostat.,

Via Campi, 4 I I 00 Modena

Batteri, funghi, virus e protozoi invadono il distretto cerebrale attraverso meccanismi molto complessi e diversi a seconda dei microrganismi. Il cervello, come ogni altro organo, è in grado di esprimere un'immunoreattività mirata ad eliminare il patogeno invasore ed eventuali cellule infettate e/o danneggiate indiretta- 
mente dalla presenza del microrganismo e quindi destinate a subire un processo di apoptosi. A differenza di organi e tessuti periferici, il cervello ha però sviluppato un proprio sistema immunitario, deputato alla difesa del SNC stesso, basato sull'attivazione di cellule residenti, le cellule gliali, localizzate in siti strategici e particolarmente vulnerabili del cervello. Tra le diverse sottopopolazioni gliali, la microglia costituisce un elemento particolarmente interessante. Definita come cellula quiescente nel SNC di un adulto sano, essa svolge in realtà una sofisticata e continua azione di sorveglianza del tessuto cerebrale ed è in grado attivarsi in maniera rapida nel caso in cui sia stato registrato un segnale di "allarme". Attraverso il ripristino della propria funzione fagocitica e il rilascio di molecole solubili (citochine, specie reattive dell'ossigeno, ecc..), la microglia dà l'inizio ad una cascata di reazioni immuni, che coinvolgono oltre alla microglia anche altre cellule e fattori solubili sia del SNC che del periferico, che insieme contribuiscono all'espletamento delle difese antimicrobiche. Questo ideale sistema di protezione del SNC presenta in realtà due punti deboli: 1) nel caso in cui lo stimolo microbico persiste a lungo e le molecole secrete dalla microglia attivata superano i valori di tolleranza da parte dell'ospite, allora l'immunoreattività del SNC diventa deleteria contribuendo pesantemente alla patogenesi della malattia, attraverso la mediazione di fenomeni di neurotossicità, con conseguente disfunzione e morte neuronale; 2) molti patogeni hanno elaborato complesse strategie di resistenza attraverso le quali il loro riconoscimento e/o eliminazione da parte dell'immunità cerebrale risulta inibito; sfuggendo alla sorveglianza immunologica locale essi si garantiscono la sopravvivenza e quindi la replicazione all'interno del SNC. L'esito di una infezione del SNC pertanto dipende sia dalla rapidità con cui le difese locali agiscono che dalla abilità del patogeno di eludere eventualmente tali sistemi antimicrobici. Una più approfondita comprensione dei complessi meccanismi che caratterizzano la patogenesi delle infezioni del SNC consentirà di disegnare interventi di profilassi e terapeutici capaci di ottimizzare la immunoreattività cerebrale salvaguardando nello stesso tempo l'omeostasi neuronale e quindi la funzionalità del SNC. 